\title{
Functional outcomes by age after inpatient stroke rehabilitation in Saudi Arabia
}

This article was published in the following Dove Press journal:

Clinical Interventions in Aging

24 October 2017

Number of times this article has been viewed

\author{
Saad M Bindawas' \\ Vishal Vennu' \\ Hussam Mawajdeh ${ }^{2}$ \\ Hisham Alhaidary ${ }^{2}$ \\ 'Department of Rehabilitation \\ Sciences, King Saud University, Riyadh, \\ ${ }^{2}$ Comprehensive Rehabilitation Care \\ Department, Rehabilitation Hospital, \\ King Fahad Medical City, Riyadh, Saudi \\ Arabia
}

Correspondence: Saad M Bindawas Department of Rehabilitation Sciences, College of Applied Medical Sciences, King Saud University, PO Box 10219 , Riyadh, 1 I433, Saudi Arabia Tel +966 || 4696226 Email sbindawas@ksu.edu.sa
Background: Among various risk factors, age has been identified as a nonmodifiable risk factor for stroke that influences functional outcomes after inpatient stroke rehabilitation in the developed world as well as in Saudi Arabia (SA). The demand for inpatient stroke rehabilitation services increases with population aging and stroke incidence; however, these services are limited in SA.

Objective: To examine functional outcomes by age after inpatient stroke rehabilitation in SA. Patients and methods: Data from 418 patients with stroke who underwent inpatient stroke rehabilitation at the King Fahad Medical City-Rehabilitation Hospital, Riyadh, SA, between November 2008 and December 2014 were collected from electronic medical records. According to the patients' age, we classified participants into two groups: adults, aged $<65$ years $(n=255)$, and older adults, aged $\geq 65$ years $(n=163)$. All patients' functional statuses at admission and discharge from inpatient stroke rehabilitation were assessed using the functional independence measure (FIM) scale.

Results: The mean age was 59.9 years $(\mathrm{SD}=9.4)$. Older adults had significantly smaller changes in functional outcome from admission to discharge on both the total FIM (23 [SD =15.9]) and the motor FIM (21 [SD =15.4]), and they were significantly less independent (36\%) compared to adults. In the adjusted models, older adults had significantly lower scores than adults, by 11 points $(p<0.0001)$ for the total FIM score and by 10 points $(p<0.0001)$ for the motor FIM subscale score. There was no significant change with age in the cognitive FIM subscale score. Conclusion: After inpatient stroke rehabilitation, older adults had limited functional outcomes or were less independent than adults. However, the clinical relevance of this finding is questionable, so there is currently no justification to deny patients access to intensive stroke rehabilitation solely because of advanced age. Future large-scale research is needed to confirm rehabilitation outcomes by including confounders such as social support, socioeconomics, comorbidities, and the patient's opinion after rehabilitation.

Keywords: adult, older adult, FIM

\section{Introduction}

Age has been identified as a nonmodifiable risk factor for stroke, and among the various risk factors, it has effects on functional outcomes after inpatient stroke rehabilitation in the developed world as well as in Saudi Arabia (SA). ${ }^{1-4}$ The risk increases with increasing age, doubling every decade after age 55 years. ${ }^{4,5}$ Studies from SA have also reported that stroke occurs with a higher incidence in the 61-70 age group, compared to the 20-40 age group. ${ }^{6,7}$ Therefore, one of the key elements in minimizing stroke and its functional limitations in the both general and elderly populations is inpatient stroke rehabilitation. ${ }^{8,9}$ 
Demand for inpatient stroke rehabilitation services has increased with aging of the population, and stroke incidence has substantially and steadily increased over the years. ${ }^{10}$ Unfortunately, inpatient stroke rehabilitation services are limited in SA; in particular, only 2 hospitals of 350 were found to have a specialized stroke team in our recent call-for-action review about stroke rehabilitation in SA. ${ }^{11}$ These hospitals provide comprehensive rehabilitation services for patients of all ages who need rehabilitation treatment services. A recent literature review on stroke in SA also demonstrated that stroke care in SA has yet to reach the levels observed in developed countries, which requires establishing stroke units, increasing public awareness, training health care providers, and enhancing collaboration. ${ }^{2}$ More recent studies have also reported that there is a high demand for more inpatient stroke rehabilitation services and relevant teams of professionals in SA.

Among several previous studies, few early studies examined the effects of age on the functional independence measure (FIM) gain as an outcome after inpatient stroke rehabilitation., ${ }^{3,10,12,13}$ The authors of these studies found that the changes in the total FIM and in subscores did not differ between young patients and the oldest patients. In SA, a prospective study was conducted on 180 patients with stroke who were referred to an active rehabilitation program between February 2008 and October 2010, with the goal of identifying the factors that possibly influence functional outcomes after inpatient rehabilitation..$^{14}$ The study results showed that rehabilitation could be effective in elderly patients with stroke and that age predicts the outcome to a lesser extent than other clinical covariates, such as the FIM score at admission. The results of studies have varied, however, regarding the methodological differences in participant type, participant age (often treated as continuous), and the length of rehabilitation. ${ }^{15,16}$

The available literature from SA supports the idea that stroke risk and related functional limitation increase with age. ${ }^{1,2,11}$ Thus, we wanted to examine functional outcomes by age, apart from the effect of functional status at admission. To this end, we evaluated two patient subgroups: those aged $<65$ years, treated as adults, and those aged $\geq 65$ years, treated as older adults.

\section{Objective}

The aim of this study was to examine functional outcomes by age after inpatient stroke rehabilitation in SA. We hypothesized that functional outcomes would differ by age after inpatient stroke rehabilitation.

\section{Patients and methods Study design}

Between November 2008 and December 2014, a review of the electronic medical record database at the King Fahad Medical City-Rehabilitation Hospital (KFMC-RH) was conducted by two of the investigators. The time frame was determined based on the availability of medical records for patients with stroke diagnosed according to the International Classification of Diseases, Ninth Revision, codes 348-438 and 799.3. Differences of opinion regarding medical records were resolved by discussion between the investigators until consensus was reached.

\section{Setting}

The KFMC-RH is the largest Ministry of Health tertiary inpatient stroke rehabilitation center in Riyadh, SA, providing free rehabilitation services to referred patients. The average duration of rehabilitation care in SA is 45 days, with the duration of care determined by age and gender. ${ }^{6}$ Data on the frequency and type of rehabilitation care were not available in the KFMC-RH database at the time of record review. However, the database also includes FIM instrument scores, which are obtained in a standardized way for all admissions and discharges.

\section{Participants}

All patients $(\mathrm{N}=418)$ aged 18 years or older who were admitted for inpatient stroke rehabilitation between November 2008 and December 2014 were considered for inclusion in this retrospective study. According to the patients' age, we classified participants into two groups: adults, aged $<65$ years $(n=255)$, and older adults, aged $\geq 65$ years $(n=163)$. This study was approved by the Committee on Human Research and the Institutional Review Board for the KFMC-RH (approval number: 14-273). The requirement for informed consent was waived because the retrospective record review was performed without contact with the subjects. Additionally, the privacy and confidentiality of individually identifiable patient health information are well established and respected by the Ministry of Health.

\section{Measurements}

Functional outcomes were evaluated with the FIM. This instrument is administered using the Uniform Data System for Medical Rehabilitation protocol, ${ }^{17}$ and it provides indices for the level of assistance required for a patient to accomplish activities of daily living. ${ }^{18}$ The FIM comprises 18 items: 13 motor items (motor FIM subscale) and 5 cognitive items 
(cognitive FIM subscale). Each item is given an ordinal score from 1 to 7. The minimum score of 1 represents complete dependence on others for that task, and the maximum score of 7 represents full independence. The total, motor, and cognitive FIM score ranges are 18-126, 13-91, and 5-35, respectively; higher scores reflect greater independence. FIM scores were sequentially measured at admission and discharge to determine the effects of therapy. The reliability and validity of the FIM for stroke patients are well established. ${ }^{19-21}$

Patient demographics included age and gender. Clinical data included stroke type (hemorrhagic and other stroke), body involvement (left, right, and bilateral), and discharge disposition (to home and not to home). Baseline functional status, complications of stroke, comorbidities, social support, and socioeconomics were not included as potential confounders because we wanted to focus on age as a predictor of functional outcomes using data available at the rehabilitation unit.

\section{Statistical analysis}

Descriptive statistics are shown as percentages for categorical measures and means with SDs for continuous measures. The chi-square test was used to analyze categorical variables, and two-sample independent $t$-tests were used to assess continuous variables to identify significant differences between the two groups. Functional category outcome changes between admission and discharge are presented as counts (percentages). Significant differences were calculated using chisquare statistics.

Individual linear regression analyses for the total FIM and its subscores (motor and cognitive FIM) were used to examine functional outcomes in older adults compared to adults. Each analysis consisted of two models: an unadjusted model (Model 1) and a model adjusted for age, gender, stroke type, body involvement, and discharge disposition (Model 2). Adults aged $<65$ years were used as the reference for all models. All analyses were performed with SAS version 9.2 (SAS Institute, Inc., Cary, NC, USA).

\section{Results}

Of the 418 patients, 255 patients were younger than 65 years (61\%) and 163 patients were aged 65 or above (39\%). All identifying characteristics of the patients are summarized in Table 1. The mean age of older adults was 72.4 years ( $\mathrm{SD}=5.9$ ), and the average length of stay in inpatient stroke rehabilitation was 48 days $(\mathrm{SD}=36.3$ ). The majority of patients were men (58\%) with hemorrhagic stroke (87\%) and left hemiparesis $(62 \%)$. Older adults were on an average of 25 years older than the adults. Older adults had a significantly
Table I Descriptive characteristics of the study participants

\begin{tabular}{|c|c|c|c|c|}
\hline Characteristics & $\begin{array}{l}\text { Total } \\
\mathrm{N}=418\end{array}$ & $\begin{array}{l}\text { Adults } \\
255(61 \%)\end{array}$ & $\begin{array}{l}\text { Older adults } \\
163(39 \%)\end{array}$ & $p$-value \\
\hline $\begin{array}{l}\text { Age in years, } \\
\text { mean } \pm S D\end{array}$ & $59.9 \pm 9.4$ & $47.5 \pm 12.9$ & $72.4 \pm 5.9$ & $<0.0001$ \\
\hline \multicolumn{5}{|l|}{ Gender } \\
\hline Male & 237 (57\%) & 143 (56\%) & 94 (58\%) & 0.75 \\
\hline Female & $|8|(43 \%)$ & II 2 (44\%) & 69 (42\%) & \\
\hline \multicolumn{5}{|l|}{ Stroke type } \\
\hline Hemorrhagic & 347 (83\%) & 205 (80\%) & I42 (87\%) & 0.07 \\
\hline Other stroke & 71 (I7\%) & $50(20 \%)$ & 21 (I3\%) & \\
\hline \multicolumn{5}{|l|}{ Body involvement } \\
\hline Left & 202 (54\%) & 110 (49\%) & 92 (62\%) & 0.024 \\
\hline Right & $|5|(40 \%)$ & 98 (44\%) & $53(35 \%)$ & \\
\hline Bilateral & $20(5 \%)$ & $16(7 \%)$ & $4(3 \%)$ & \\
\hline \multicolumn{5}{|l|}{ Discharge setting } \\
\hline To home & 406 (97\%) & $250(98 \%)$ & 156 (96\%) & 0.16 \\
\hline Not to home & $12(3 \%)$ & $5(2 \%)$ & $7(4 \%)$ & \\
\hline $\mathrm{LOS}$, mean $\pm \mathrm{SD}$ & $47.5 \pm 31.1$ & $47.0 \pm 25.9$ & $48.0 \pm 36.3$ & 0.94 \\
\hline \multicolumn{5}{|l|}{ Motor FIM score } \\
\hline IRF admission & $34.5 \pm 17.7$ & $38.0 \pm 19.1$ & $31.0 \pm 16.4$ & 0.0002 \\
\hline IRF discharge & $57.5 \pm 22.4$ & $63.0 \pm 21.6$ & $52.0 \pm 23.3$ & $<0.0001$ \\
\hline Change & $23.0 \pm 15.3$ & $25.0 \pm 15.3$ & $21.0 \pm 15.4$ & 0.011 \\
\hline \multicolumn{5}{|c|}{ Cognitive FIM score } \\
\hline IRF admission & $26.0 \pm 9.2$ & $26.0 \pm 9.3$ & $26.0 \pm 9.2$ & 0.78 \\
\hline IRF discharge & $28.5 \pm 7.7$ & $29.0 \pm 7.7$ & $28.0 \pm 7.8$ & 0.25 \\
\hline Change & $2.5 \pm 3.8$ & $3.0 \pm 3.9$ & $2.0 \pm 3.8$ & 0.09 \\
\hline \multicolumn{5}{|l|}{ Total FIM score } \\
\hline IRF admission & $60.5 \pm 23.1$ & $64.0 \pm 24.4$ & $57.0 \pm 21.8$ & 0.003 \\
\hline IRF discharge & $85.5 \pm 27.0$ & $91.0 \pm 26.2$ & $80.0 \pm 27.9$ & $<0.0001$ \\
\hline Change & $25.0 \pm 16.2$ & $27.0 \pm 16.6$ & $23.0 \pm 15.9$ & 0.005 \\
\hline FIM efficiency & $8.0 \pm 9.4$ & $6.0 \pm 14.3$ & $4.0 \pm 4.5$ & 0.18 \\
\hline
\end{tabular}

Note: Data presented as mean \pm standard deviation or $\mathrm{n}(\%)$.

Abbreviations: FIM, functional independence measure; IRF, inpatient rehabilitation facility; LOS, length of stay.

lower total FIM score (mean: 91 vs $80, p<0.0001$ ) and motor FIM subscale score (mean: 63 vs 52, $p<0.0001$ ) at discharge. The average changes from admission to discharge in the total FIM score ( 27 vs $23, p=0.005$ ) and motor FIM score ( 25 vs $21, p=0.011$ ) significantly differed by age.

Figure 1 shows the outcomes according to the FIM score by functional category, stratified by age group. There were significant increases in the functional level in all three categories. From admission to discharge, older adults exhibited a 33\% decrease in the maximum assistance category, a 3\% reduction in the moderate assistance category, and a $36 \%$ increase in the minimal-to-no-assistance category $(p=0.001)$ compared to adults, who respectively showed $32 \%, 13 \%$, and $45 \%$ decreases $(p=0.005)$. Overall, all stroke rehabilitation participants exhibited a $33 \%$ decrease in the maximum assistance category, a 9\% reduction in the moderate assistance category, and a $42 \%$ increase in the minimal-to-no-assistance category $(p<0.0001)$ from admission to discharge. 

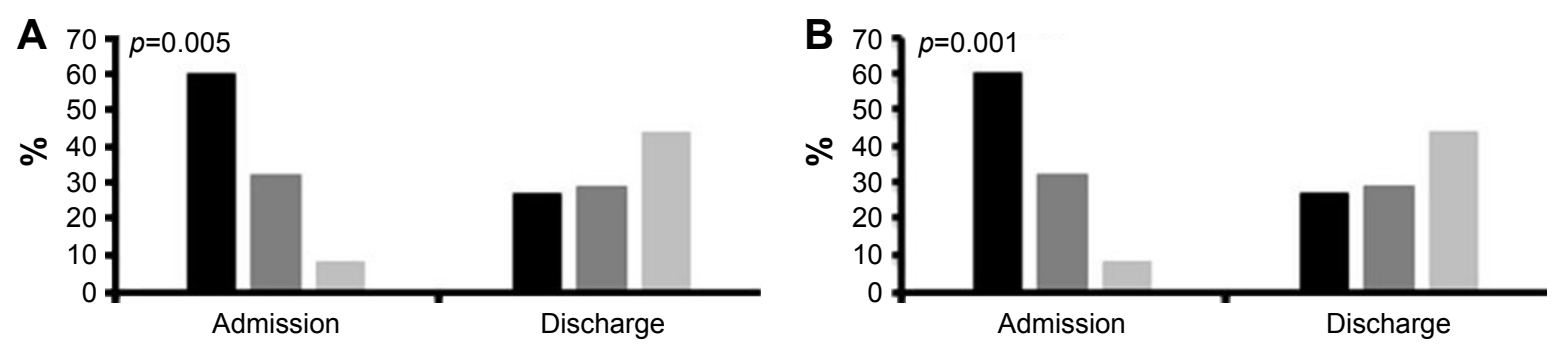

Max assist Mod assist Min to no assist

Figure I Percentages of individuals in the functional categories (maximum assistance to minimum to no assistance) at admission and discharge among (A) adults and (B) older adults.

Outcomes confirmed by regression analyses of the total FIM (Table 2), motor FIM (Table 3), and cognitive FIM (Table 4) are presented for older adults compared to adults. In the unadjusted model, older adults had significantly lower scores, which were 11.5 points $(p<0.0001)$ lower for the total FIM score and 11 points $(p<0.0001)$ lower for the motor FIM subscale score. In the adjusted model, older adults had significantly lower scores, which were 11 points $(p<0.0001)$ lower for the total FIM score and 10 points $(p<0.0001)$ lower for the motor FIM subscale score. There was no significant change by age in the cognitive FIM subscale score.

\section{Discussion}

This study aimed to examine the functional outcomes by age after inpatient stroke rehabilitation in SA. After inpatient stroke rehabilitation, older adults were significantly less independent than adults. Furthermore, regression analyses revealed that older age was significantly associated with lower scores on the total FIM and motor FIM after discharge from inpatient stroke rehabilitation, even after adjusting

Table 2 Regression analysis of the total FIM scores of older adults with stroke after discharge from an inpatient rehabilitation unit

\begin{tabular}{|c|c|c|c|c|c|c|}
\hline \multirow[t]{2}{*}{ Characteristic } & \multicolumn{3}{|c|}{ Model I $(n=4 \mid 8)$} & \multicolumn{3}{|c|}{ Model $2(n=373)$} \\
\hline & $\beta$ & SE & $p$-value & $\beta$ & SE & $p$-value \\
\hline Constant & 85.8 & 1.35 & $<0.000 \mathrm{I}$ & 86.0 & 4.39 & $<0.0001$ \\
\hline Older adults vs adults & -11.5 & 2.69 & $<0.0001$ & -11.0 & 2.79 & $<0.0001$ \\
\hline Gender (male vs female) & & & & 7.34 & 2.72 & 0.007 \\
\hline $\begin{array}{l}\text { Stroke type (hemorrhagic } \\
\text { vs other stroke) }\end{array}$ & & & & 0.03 & 0.40 & 0.94 \\
\hline $\begin{array}{l}\text { Body involvement (left or } \\
\text { right vs bilateral) }\end{array}$ & & & & 0.50 & 2.29 & 0.83 \\
\hline $\begin{array}{l}\text { Discharge disposition } \\
\text { (not to home vs to home) }\end{array}$ & & & & -4.0 & 0.98 & $<0.000$ I \\
\hline$R^{2}$ & 0.042 & & & 0.10 & & \\
\hline
\end{tabular}

Abbreviations: FIM, functional independence measure; SE, standard error. for gender, stroke type, body involvement, and discharge disposition.

Among other factors, age is an important nonmodifiable prognostic factor, and several previous studies have accordingly shown that younger patients had better outcomes. ${ }^{22-29}$ In this study, older adults had significantly lower scores on the total FIM and the motor FIM alone. In contrast, there was no significant association for the cognitive FIM. This result may be due to the fact that predicting rehabilitation outcomes in older adults with stroke can be difficult due to several clinical modifiers, such as comorbidity, medical complications, neuropsychologic impairment appropriate to the aging brain, and social concern. ${ }^{30}$ Successful inpatient stroke rehabilitation for older adults may require more comprehensive programs over a longer period. ${ }^{31}$

In contrast to the effect of age, the confounder gender (male vs female) was related to significant improvement in the total FIM score and motor FIM subscale score at discharge, as has been reported in previous studies. ${ }^{32,33}$ Additionally, the confounder body involvement was related to less

Table 3 Regression analysis of the motor FIM scores of older adults with stroke after discharge from an inpatient rehabilitation unit

\begin{tabular}{|c|c|c|c|c|c|c|}
\hline \multirow[t]{2}{*}{ Characteristic } & \multicolumn{3}{|c|}{ Model I $(n=4 \mid 8)$} & \multicolumn{3}{|c|}{ Model $2(n=373)$} \\
\hline & $\beta$ & SE & $p$-value & $\beta$ & SE & $p$-value \\
\hline Constant & 57.4 & 1.12 & $<0.0001$ & 54.1 & 3.65 & $<0.0001$ \\
\hline Older adults vs adults & -11.0 & 2.23 & $<0.0001$ & -10.0 & 2.32 & $<0.0001$ \\
\hline Gender (male vs female) & & & & 7.0 & 2.27 & 0.002 \\
\hline Stroke type (hemorrhagic & & & & -0.01 & 0.33 & 0.97 \\
\hline \multicolumn{7}{|l|}{ vs other stroke) } \\
\hline Body involvement (left or & & & & 0.91 & 1.90 & 0.32 \\
\hline \multicolumn{7}{|l|}{ right vs bilateral) } \\
\hline Discharge disposition & & & & -3.0 & 0.81 & 0.0002 \\
\hline \multicolumn{7}{|l|}{ (not to home vs to home) } \\
\hline$R^{2}$ & 0.052 & & & 0.11 & & \\
\hline
\end{tabular}


Table 4 Regression analysis of the cognitive FIM scores of older adults with stroke after discharge from an inpatient rehabilitation unit

\begin{tabular}{|c|c|c|c|c|c|c|}
\hline \multirow[t]{2}{*}{ Characteristic } & \multicolumn{3}{|c|}{ Model I $(n=4 \mid 8)$} & \multicolumn{3}{|c|}{ Model $2(n=373)$} \\
\hline & $\beta$ & SE & $p$-value & $\beta$ & SE & $p$-value \\
\hline Constant & 28.3 & 0.38 & $<0.0001$ & 31.6 & 1.25 & $<0.0001$ \\
\hline Older adults vs adults & -0.89 & 0.77 & 0.25 & -0.89 & 0.79 & 0.26 \\
\hline Gender (male vs female) & & & & 0.27 & 0.77 & 0.73 \\
\hline $\begin{array}{l}\text { Stroke type (hemorrhagic } \\
\text { vs other stroke) }\end{array}$ & & & & 0.04 & 0.11 & 0.73 \\
\hline $\begin{array}{l}\text { Body involvement (left or } \\
\text { right vs bilateral) }\end{array}$ & & & & $-|.4|$ & 0.65 & 0.031 \\
\hline $\begin{array}{l}\text { Discharge disposition } \\
\text { (not to home vs to home) }\end{array}$ & & & & -0.96 & 0.27 & 0.0006 \\
\hline$R^{2}$ & 0.003 & & & 0.049 & & \\
\hline
\end{tabular}

Abbreviations: FIM, functional independence measure; SE, standard error.

improvement in the cognitive FIM subscale score, similar to the findings of other studies, which revealed that cognitive recovery is more limited with increasing age. ${ }^{31,34}$ Another confounder, discharge disposition, was related to significantly less improvement in the total FIM and its domains (motor and cognitive) in patients who were not discharged to home, perhaps because of predictive factors such as prestroke living arrangement (lived alone vs lived not alone), as previously hypothesized by other authors. ${ }^{35}$

The study findings were similar to those of previous studies..$^{10,22,23,36-38}$ The results of these studies confirmed that older adults had lower FIM scores. Additionally, the findings of these studies confirmed that a higher FIM score on admission is associated with higher scores on discharge. One example is an early prospective study performed in Canada, which demonstrated that age alone was a significant predictor of the total FIM score and motor FIM score at discharge. ${ }^{10}$ However, this study's methodology, such as the participant type and the composition of the inpatient rehabilitation program, differed from that of our study. A recent systematic literature review that was performed between January 2000 and October 2015 in the Netherlands demonstrated that young age was significantly associated with better functional outcomes at discharge. ${ }^{22}$ Another study that was performed in Istanbul showed that age was a significant predictor of the total FIM score and motor FIM score at discharge.${ }^{36}$ However, apart from the effect of functional status at admission, functional outcomes according to age categories after inpatient stroke rehabilitation in SA have not been examined.

The findings of this study have significant implications for developing stroke rehabilitation services in SA to achieve better functional outcomes among older adults with stroke. In SA, Al-Jadid and Robert reported that stroke occurred at a higher frequency in the 61-70 age group and had lower rates in the $20-30$ and $31-40$ age groups. ${ }^{6}$ Another study from SA also reported that stroke most often occurred in the 61-70 age group, whereas the 30-40 age group was least affected. ${ }^{?}$ Additionally, a survey was conducted in SA to assess the level of stroke awareness in the Saudi adult population. ${ }^{39}$ The findings of that study suggest that there is an alarming deficit in the standard of stroke knowledge among Saudi adults.

\section{Study limitations and strengths}

Our study had certain limitations. First, the findings cannot be generalized to all people because this was a single-center study. Second, causality cannot be determined because the study was retrospective. Third, the data were limited because they did not include potential confounders, such as marital status, education, living status, race, social support, functional status at admission, stroke severity, comorbidity, depressive symptoms, and body mass index. Finally, as this was a retrospective study, patients were preselected for admission because they were regarded as likely to benefit from stroke rehabilitation. The strength of the study is that the KFMC-RH is a large tertiary inpatient stroke rehabilitation hospital in Riyadh, SA, with a license to use the FIM scale, which has the highest reliability and validity among the methods of evaluating activities of daily living and is widely used in rehabilitation settings. ${ }^{8,26,40-42}$

\section{Conclusion}

After inpatient stroke rehabilitation, older adults had limited functional outcomes or were less independent than adults. However, the clinical relevance of this finding is questionable, so there is currently no justification to deny patients access to intensive stroke rehabilitation solely because of advanced age. Future large-scale research is needed to confirm rehabilitation outcomes by including confounders such as social support, socioeconomics, comorbidities, and the patient's opinion after rehabilitation. In any case, the knowledge obtained in this study may be applied to establish new comprehensive rehabilitation centers in SA for older adults with stroke.

\section{Acknowledgments}

The authors extend their appreciation to the Research Centre, College of Applied Medical Sciences, and the Deanship of Scientific Research at King Saud University for funding this research.

\section{Disclosure}

The authors report no conflicts of interest in this work. 


\section{References}

1. Bindawas SM, Mawajdeh H, Vennu V, Alhaidary H. A retrospective observational study of functional outcomes, length of stay, and discharge disposition after an inpatient stroke rehabilitation program in Saudi Arabia. Medicine (Baltimore). 2016;95(31):e4432.

2. Robert AA, Zamzami MM. Stroke in Saudi Arabia: a review of the recent literature. Pan Afr Med J. 2014;17:14.

3. Kim TH, Vemuganti R. Effect of sex and age interactions on functional outcome after stroke. CNS Neurosci Ther. 2015;21(4):327-336.

4. Wong R, Bath PM, Kendall D, Gibson CL. Progesterone and cerebral ischaemia: the relevance of ageing. J Neuroendocrinol. 2013;25(11): 1088-1094.

5. Rojas JI, Zurru MC, Romano M, Patrucco L, Cristiano E. Acute ischemic stroke and transient ischemic attack in the very old - risk factor profile and stroke subtype between patients older than 80 years and patients aged less than 80 years. Eur J Neurol. 2007;14(8):895-899.

6. Al-Jadid MS, Robert AA. Determinants of length of stay in an inpatient stroke rehabilitation unit in Saudi Arabia. Saudi Med J. 2010; 31(2):189-192.

7. Al-Eithan MH, Amin M, Robert AA. The effect of hemiplegia/ hemiparesis, diabetes mellitus, and hypertension on hospital length of stay after stroke. Neurosciences (Riyadh). 2011;16(3):253-256.

8. Denti L, Agosti M, Franceschini M. Outcome predictors of rehabilitation for first stroke in the elderly. Eur J Phys Rehabil Med. 2008; 44(1):3-11.

9. Cameron JI, Tsoi C, Marsella A. Optimizing stroke systems of care by enhancing transitions across care environments. Stroke. 2008;39(9): 2637-2643.

10. Bagg S, Pombo AP, Hopman W. Effect of age on functional outcomes after stroke rehabilitation. Stroke. 2002;33(1):179-185.

11. Bindawas SM, Vennu VS. Stroke rehabilitation. A call to action in Saudi Arabia. Neurosciences (Riyadh). 2016;21(4):297-305.

12. Black-Schaffer RM, Winston C. Age and functional outcome after stroke. Top Stroke Rehabil. 2004;11(2):23-32.

13. Nazzal ME, Saadah MA, Trebinjac SM, Al-Awadi OA, Al-Shamsi KA. Effect of risk factors on functional outcome after stroke rehabilitation. Neurosciences (Riyadh). 2006;11(1):15-20.

14. Abdul-sattar AB, Godab T. Predictors of functional outcome in Saudi Arabian patients with stroke after inpatient rehabilitation. NeuroRehabilitation. 2013;33(2):209-216.

15. Al Jadid MS. Rehabilitation medicine in the Kingdom of Saudi Arabia. Saudi Med J. 2011;32(9):962-963.

16. Al-Jadid MS. Disability in Saudi Arabia. Saudi Med J. 2013;34(5): 453-460.

17. Galloway RV, Granger CV, Karmarkar AM, et al. The Uniform Data System for Medical Rehabilitation: report of patients with debility discharged from inpatient rehabilitation programs in 2000-2010. Am J Phys Med Rehabil. 2013;92(1):14-27.

18. Keith RA, Granger CV, Hamilton BB, Sherwin FS. The functional independence measure: a new tool for rehabilitation. Adv Clin Rehabil. 1987;1:6-18.

19. Dodds TA, Martin DP, Stolov WC, Deyo RA. A validation of the functional independence measurement and its performance among rehabilitation inpatients. Arch Phys Med Rehabil. 1993;74(5):531-536.

20. Nichols DS, Miller L, Colby LA, Pease WS. Sitting balance: its relation to function in individuals with hemiparesis. Arch Phys Med Rehabil. 1996;77(9):865-869.

21. Ring H, Feder M, Schwartz J, Samuels G. Functional measures of first-stroke rehabilitation inpatients: usefulness of the Functional Independence Measure total score with a clinical rationale. Arch Phys Med Rehabil. 1997;78(6):630-635.

22. Everink IH, van Haastregt JC, van Hoof SJ, Schols JM, Kempen GI. Factors influencing home discharge after inpatient rehabilitation of older patients: a systematic review. BMC Geriatr. 2016;16:5.
23. Louie SW, Wong SK, Wong CM. Profiles of functional outcomes in stroke rehabilitation for Chinese population: a cluster analysis. NeuroRehabilitation. 2009;25(2):129-135.

24. Joa KL, Han TR, Pyun SB, et al. Inpatient stroke rehabilitation outcomes in Korea derived from the Korean Brain Rehabilitation Centers' online database system for the years 2007 to 2011. J Korean Med Sci. 2015;30(5):644-650.

25. Mutai H, Furukawa T, Araki K, Misawa K, Hanihara T. Factors associated with functional recovery and home discharge in stroke patients admitted to a convalescent rehabilitation ward. Geriatr Gerontol Int. 2012;12(2):215-222.

26. Ng YS, Stein J, Ning M, Black-Schaffer RM. Comparison of clinical characteristics and functional outcomes of ischemic stroke in different vascular territories. Stroke. 2007;38(8):2309-2314.

27. Heruti RJ, Lusky A, Dankner R, et al. Rehabilitation outcome of elderly patients after a first stroke: effect of cognitive status at admission on the functional outcome. Arch Phys Med Rehabil. 2002;83(6):742-749.

28. Ostwald SK, Swank PR, Khan MM. Predictors of functional independence and stress level of stroke survivors at discharge from inpatient rehabilitation. J Cardiovasc Nurs. 2008;23(4):371-377.

29. Franceschini M, La Porta F, Agosti M, Massucci M. Is healthrelated-quality of life of stroke patients influenced by neurological impairments at one year after stroke? Eur J Phys Rehabil Med. 2010; 46(3):389-399.

30. Hazzard WR. Principles of Geriatric Medicine and Gerontology. 4th ed. New York: McGraw-Hill, Health Professions Division; 1999.

31. Duncan PW, Zorowitz R, Bates B, et al. Management of Adult Stroke Rehabilitation Care: a clinical practice guideline. Stroke. 2005;36(9): e100-e143.

32. Appelros P, Stegmayr B, Terent A. A review on sex differences in stroke treatment and outcome. Acta Neurol Scand. 2010;121(6):359-369.

33. Paolucci S, Bragoni M, Coiro P, et al. Is sex a prognostic factor in stroke rehabilitation? A matched comparison. Stroke. 2006;37(12): 2989-2994.

34. O'Brien SR, Xue Y. Predicting goal achievement during stroke rehabilitation for Medicare beneficiaries. Disabil Rehabil. 2014;36(15): 1273-1278.

35. Tanwir S, Montgomery K, Chari V, Nesathurai S. Stroke rehabilitation: availability of a family member as caregiver and discharge destination. Eur J Phys Rehabil Med. 2014;50(3):355-362.

36. Ones K, Yalcinkaya EY, Toklu BC, Caglar N. Effects of age, gender, and cognitive, functional and motor status on functional outcomes of stroke rehabilitation. NeuroRehabilitation. 2009;25(4):241-249.

37. Tur BS, Gursel YK, Yavuzer G, Kucukdeveci A, Arasil T. Rehabilitation outcome of Turkish stroke patients: in a team approach setting. Int J Rehabil Res. 2003;26(4):271-277.

38. Mokler PJ, Sandstrom R, Griffin M, Farris L, Jones C. Predicting discharge destination for patients with severe motor stroke: important functional tasks. Neurorehabil Neural Repair. 2000;14(3):181-185.

39. Alaqeel A, AlAmmari A, AlSyefi N, Al-Hussain F, Mohammad Y. Stroke awareness in the Saudi community living in Riyadh: prompt public health measures must be implemented. J Stroke Cerebrovasc Dis. 2014;23(3):500-504.

40. Gosselin S, Desrosiers J, Corriveau H, et al. Outcomes during and after inpatient rehabilitation: comparison between adults and older adults. $J$ Rehabil Med. 2008;40(1):55-60.

41. Ergeletzis D, Kevorkian CG, Rintala D. Rehabilitation of the older stroke patient: functional outcome and comparison with younger patients. Am J Phys Med Rehabil. 2002;81(12):881-889.

42. Falconer JA, Naughton BJ, Strasser DC, Sinacore JM. Stroke inpatient rehabilitation: a comparison across age groups. J Am Geriatr Soc. 1994;42(1):39-44. 
Clinical Interventions in Aging

\section{Publish your work in this journal}

Clinical Interventions in Aging is an international, peer-reviewed journal focusing on evidence-based reports on the value or lack thereof of treatments intended to prevent or delay the onset of maladaptive correlates of aging in human beings. This journal is indexed on PubMed Central, MedLine,

CAS, Scopus and the Elsevier Bibliographic databases. The manuscript management system is completely online and includes a very quick and fair peer-review system, which is all easy to use. Visit http://www.dovepress. $\mathrm{com} /$ testimonials.php to read real quotes from published authors.

Submit your manuscript here: http://www.dovepress.com/clinical-interventions-in-aging-journal 